\title{
Design and Implementation of College English Teaching Resources Database System*
}

\author{
Jian Gong ${ }^{1}$ \\ Henan University
}

\begin{abstract}
Universities recently use cloud computing technology to build a cloud computing College English teaching resource platform to share teaching resources and improve the use of College English teaching resources. Through the analysis of cloud computing and its application is in colleges and universities, this paper explores the problems in the construction of digital College English teaching resources in colleges and universities, and proposes how to build cloud computing-based colleges and universities for how to make use of the advantages of cloud computing in college teaching resources. We introduce the concept of the construction of teaching resources platform, and discuss the overall architecture of the platform, the establishment of resource pool, the construction of service platform, the construction of service system and the upgrading of platform functions.
\end{abstract}

\section{Keywords}

College English Teaching Resources $\bullet$ Cloud Computing $\bullet$ Dataset System $\bullet$ Service Platform

\footnotetext{
* This work is supported by the training program for key young teachers of Institutions of higher learning of Henan in 2017.

${ }^{1}$ Correspondence to: Jian Gong (MA), Henan University of Animal Husbandry and Economy, Zhengzhou 450044, China. Email: tongtong88flora@ hotmail.com
} 
Cloud computing is a pay-per-use model that provides available, convenient, on-demand network access to a configurable pool of computing resource resources that can be provisioned quickly and with minimal investment. Manage work, or have little interaction with service providers. Cloud computing includes the following three levels of services: Infrastructure as a Service (IaaS), Platform as a Service (PaaS) and Software as a Service (SaaS) (Tan \& Hsu, 2018; Zhang, 2017). IaaS means that consumers can obtain services from a comprehensive computer infrastructure through the Internet; PaaS refers to the platform of software development as a service; SaaS is a mode of providing software through the Internet, users do not need to purchase software, but provide Merchants rent Web-based software (James, Matthew \& Samrachana, 2018; Freire \& Painho, 2014).

Cloud services are generally divided into public cloud, private cloud, and hybrid cloud. Public cloud refers to the provision of external network services through the Internet; private cloud refers to services that can be used only within the enterprise; hybrid cloud refers to private clouds combined with public clouds. This is a service that uses the public cloud when the resources of the private cloud are insufficient. Get support. One is that cloud computing is scalable. The scale of cloud computing can be continuously expanded according to demand, and can be stretched. The second is that cloud computing is versatile. Cloud computing is fully functional and can operate in a variety of different areas. The third is cloud computing with stability. Cloud computing is managed by professionals, so data resources are relatively secure. Cloud computing is faulttolerant and fails. The cloud management system will quickly find errors, recover quickly, and ensure stability. Fourth, cloud computing is virtual (Lee, 2012; Terhart, 2013; Ma, Steger, Doolittle \& Stewart, 2018). On the cloud service platform, cloud computing virtualization technology is used to virtualize and store all kinds of resources, and the required services can be obtained after login. Fifth, cloud computing has reliability. In cloud computing, adopt effective fault-tolerant security measures and exchange measures, arrange professional personnel to maintain data, maintain security, prevent hacker attacks, prevent data loss, prevent virus intrusion, ensure service, and ensure security. Sixth, the cost of cloud computing is low. Cloud computing uses automated management methods to manage computer data centers, resulting in fewer computing cycles, high operational efficiency, time savings, cost savings, and significant cost reductions.

In the application of university informatization, cloud computing provides teaching services to teachers, students, and teaching administrators through infrastructure, software, and other forms, so that they can access a variety of teaching resources at any time and can achieve the highest efficiency of teaching resources. Change Cloud computing accesses the configurable computing resource pool through the network. With minimal management work or services, it can quickly provide teaching resources for teachers, students, and education administrators. The cloud computing data storage system is widely used in the field of university teaching and it provides higher performance services to teachers, students and teaching managers (Sinnema \& Fevre, 2013; Tang, 2016). The redundant teaching method ensures that the stored teaching resource data is more reliable and can be used by teachers, students, and teaching managers. Users provide teaching and learning services (Acharya, et al. 2013). Therefore, cloud computing can effectively promote the construction of university teaching informatization. The cloud computing has great potential and has the ability to change the teaching information service of colleges and universities. 


\section{College English Teaching Resources Database System Framework Design}

\section{Project Management Theory and Methods}

The project is a temporary activity to create a unique product or service. Project management is the scientific and standardized management of system using management methods and tools in project activities. Effective project management is to plan, guide, and control the organization's resources within the time it takes to achieve specific goals and targets. The essence of this is project execution with the highest possible benefits (Cook, 2014; Gaudencio, Dantas, \&Guerrero, 2014). The basic theory of project management is mainly reflected in its management process and management content.

Project managers usually divide the project into several stages for effective control and management. The project management process is implemented by the project team. In most cases, most projects have a common project management process. From the perspective of time, project management is divided into five major processes, each of which contains one or more programs. The five project management processes are not completely separated. The result or output of a process is often the input of the next process. From the beginning of the project to the end of this process, the processes will overlap and interact with each other to varying degrees. Among them, the project planning process group is an important and burdensome process group. Although in the implementation process, the project planning will inevitably appear to adjust and change, but doing a good job in all aspects of the project planning is a necessary prerequisite for project management. The project management process and the overlapping relationship are shown in Figure 1.

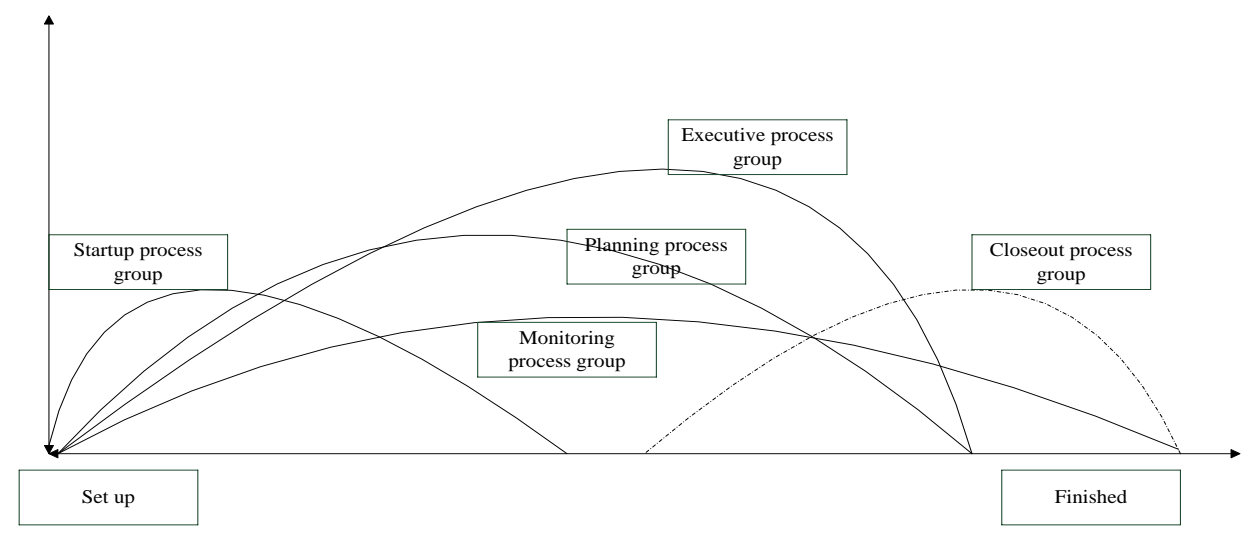

Figure 1. Project Management Process and Overlapping Relationship.

The comprehensive nature of project management requires that each project process be properly matched and linked with other processes. Only in this way its coordination may be facilitated. A process can determine and constrain how the process uses existing evidence to create outcomes. These interactions and roles between each process often require the weighing of various project requirements and goals. 
In daily life, we start or start a thing as "startup", but in project management, the start flag is that the project is approved. The start-up of a project includes two layers of meaning. The first is to formally identify a new project, and the second is to determine whether an already-executed project will enter a new phase. In the startup process group description of the U.S. Project Management Institute, the project start-up process requires two outcomes to develop a project charter and develop a preliminary project specification. The project charter is an authorization document issued by an organization, plan, or a comprehensive action management agency outside the project team. It will document the needs of the project and plan to meet the project's requirements for products, services, or other forms of results. The preliminary scope statement of the project is the process of using the project charter and other relevant data to define the high level of the project. The specification will further conceptually describe project deliverables, project definition, acceptance methods, and scope controls. Therefore, this process has often started with the involvement of the project management team. In this process, extensively listening to the opinions of project stakeholders will have a positive impact on the initiation of the project and the entire process. At the start of the project, special emphasis should be placed on grasping the key points to correctly determine the feasibility of the project and objectively analyzing the project organization's ability to bear the ability to fully discuss and sign the project contract with the organization that has the necessary capabilities for the project.

\section{Cloud computing-based university teaching resources architecture model}

Cloud computing combines a large number of virtualized resources into a large resource pool through the network to provide users with a unified service. The goal of the cloud computing-based digital teaching resource platform design is to use virtualization technology to encapsulate the university's teaching resources and their hardware and software infrastructure into a resource pool to complete the integration and sharing of various teaching resource platforms and their resources. To achieve unified management and scheduling of colleges and universities hardware and software resources, and to provide cloud services to users through the client. The cloud computing-based university teaching resource platform architecture model is divided into two layers, as shown in Figure 2.

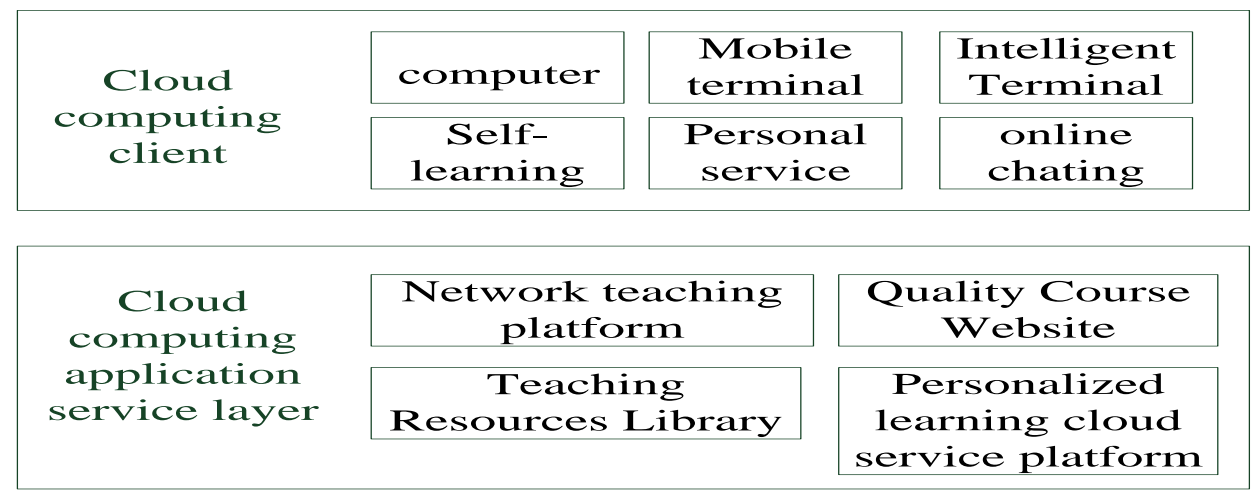

Figure 2. Cloud computing-based university teaching resources platform architecture model. 
The cloud computing client refers to various hardware and software devices used to access cloud computing services, including terminal devices such as personal computers, smart phones, and tablet computers. Users can access the teaching resource platform to obtain related services through these terminal devices. The cloud computing application service layer mainly integrates the existing high-quality online teaching resources, mainly including excellent course websites, online teaching platforms, teaching resource libraries, and personalized learning cloud service platforms. It also provides end users with various Internet software services and applications.

\section{Results and discussion}

\section{College English Teaching Resources Database System Status}

According to the results of the questionnaire survey, the results of the descriptive statistics of the overall needs of university students on the resource pool are shown in Table 1 and Table 2. From the table, it can be seen that the overall demand of college students for the resource pool is divided into 3.13, which is between "3 (more consistent) - 4 (very consistent)" and exceeds the degree of more needed, indicating that college students have the overall demand for professional teaching resources is relatively large. From the perspective of the subdimensions of resource requirements, the demand for learning resources, social needs, and the need for problem solving in colleges and universities are all in the range of 3 (Comparable) - 4 (very consistent)" indicates that college students have a greater need to these three dimensions.

After independent sample t-test, there was no difference between male and female students in the demand for resource pools in colleges and universities $(\mathrm{t}=0.385>0.05)$. It Sends a message that the gender demand for resource pools did not produce significant results. Impact, see Table 2.

Table 1

An Analysis of College Students of English Major's Needs for Learning Resources in Resource Banks

\begin{tabular}{lccccc}
\hline Dimensions & $\mathrm{N}$ & Minimum & Maximum & Average & S.d. \\
\hline Need for learning resources & 750 & 1 & 4 & 3.11 & 0.41 \\
Social needs & 750 & 1 & 4 & 3.12 & 0.52 \\
The need for problem solving & 750 & 1 & 4 & 3.17 & 0.54 \\
Demand for the repository & 750 & 1 & 4 & 3.14 & 0.43 \\
\hline
\end{tabular}

Table 2

Differences in Demand for Resources from Students of Different Sex Concerned

\begin{tabular}{llcccc}
\hline & & $\mathrm{N}$ & Average & S.d. & $\mathrm{T}$ \\
\hline \multirow{2}{*}{ Gender } & Male & 400 & 3.14 & 0.48 & 0.87 \\
& Female & 350 & 3.11 & 0.38 & \\
\hline
\end{tabular}

To learn, students must have corresponding learning resources to support them. Therefore, learning resources can be said to be a necessary material basis for learners to learn. The article analyzes the characteristics of the demand for learning resources. It contains a total of 10 observation points, and each observation point has a question (that is, the 1 to 10 questions in the questionnaire). The survey of resource requirements of resource pools by higher vocational students is shown in Table 3. 
Table 3

An Analysis of College Students of English Major's Needs for Learning Resources in Resource Banks

\begin{tabular}{lccccc}
\hline Questions & $\mathrm{N}$ & Minimum & Maximum & Average & S.d. \\
\hline Q1 & 750 & 1 & 4 & 3.04 & 0.649 \\
Q2 & 750 & 1 & 4 & 3.01 & 0.715 \\
Q3 & 750 & 1 & 4 & 2.74 & 0.725 \\
Q4 & 750 & 1 & 4 & 3.14 & 0.718 \\
Q5 & 750 & 1 & 4 & 3.36 & 0.652 \\
Q6 & 750 & 1 & 4 & 3.12 & 0.701 \\
Q7 & 750 & 1 & 4 & 3.27 & 0.669 \\
Q8 & 750 & 1 & 4 & 3.32 & 0.674 \\
Q9 & 750 & 1 & 4 & 3.21 & 0.669 \\
Q10 & 750 & 4 & 2.94 & 0.735 \\
\hline
\end{tabular}

The above table sends the average of the two questions is less than 3 (more consistent) W, other various items the mean is higher than 3 (more consistent). According to the analysis of each item, $84.6 \%$ of students like to learn professional knowledge (Q4) through actual cases, and $92.3 \%$ of students prefer to train and improve their professional skills in real situations (Q5) $91 \%$ of students believe that motivated learning tasks can mobilize their enthusiasm (Q7), and $91.6 \%$ of students believe that pictures and video resources are more conducive to their understanding of the work process (Q8). The choice of each item is also mostly distributed in the two options "Compatible" and "Very Consistent".

The preference of university students for learning resources can be seen in the fact that university students tend to use online learning resources, compared to such diverse and rich online resources, boring traditional resources (paper textbooks, handouts, etc.) Slightly inferior. The contents of the professional teaching resources library in higher vocational schools can theoretically include all the requirements of higher vocational students for learning resources, such as micro-teaching videos, picture materials, case materials, and creation of virtual environments.

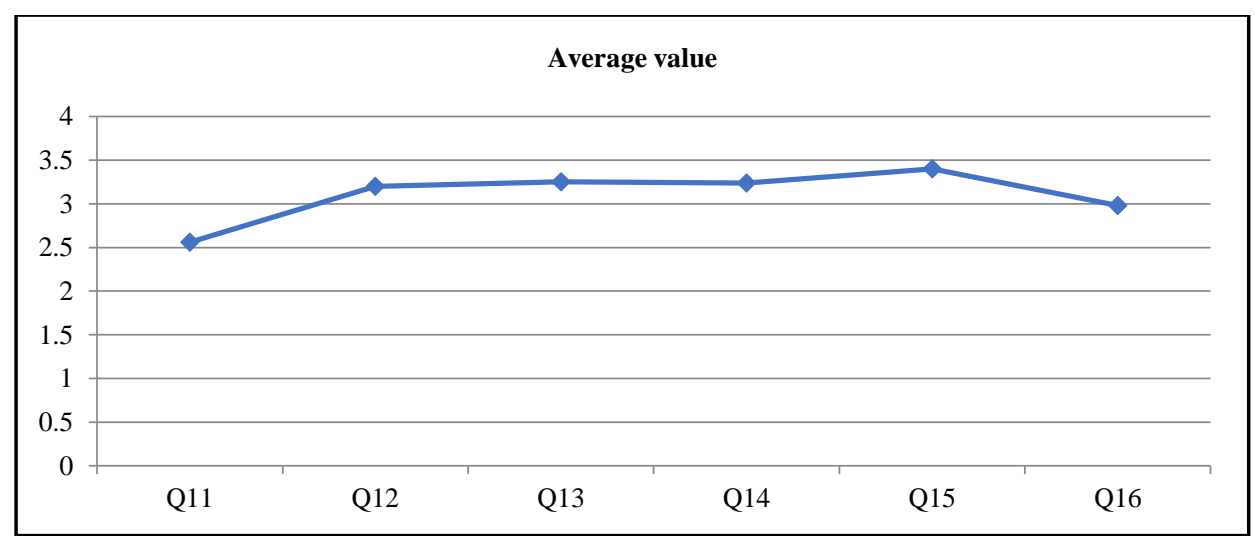

Figure 3. Demand for social resources of resource pools by university students.

Communicating with others enables higher vocational students to learn more efficiently. Today's classrooms also promote diverse social activities. The enthusiasm of the classroom is very valuable. Based on the analysis in Chapter 2, this study analyzes the characteristics of their social resource needs. It contains a total of 6 opinions, 
and each observation point has a question (ie, 11-16 questions in the questionnaire). The investigation of the demand for social resources of resource pools by higher vocational students is shown in Figure 3.

From the analysis of results, nearly $50 \%$ of students do not like to ask questions from teachers. Only $10 \%$ of students often ask questions to teachers $(\mathrm{QU})$, but most students are happy to help others solve problems (90.2\%, Q12) and hope to have the teacher or classmate helped solve the problem (90.9\%, Q13), and most of the students (92.2\%) tended to communicate with friends left through social networks such as WeChat and QQ (Q15). .

This shows that in terms of the demand for social resources, nearly half of the students are relatively excluded from the face-to-face interaction issues with teachers, but in terms of professional learning, they are also eager to get the help of teachers and classmates, which is also understandable in social in the media. Thant is why they tend to socialize online, but they want to solve the problems that arise in professional learning through the Internet.

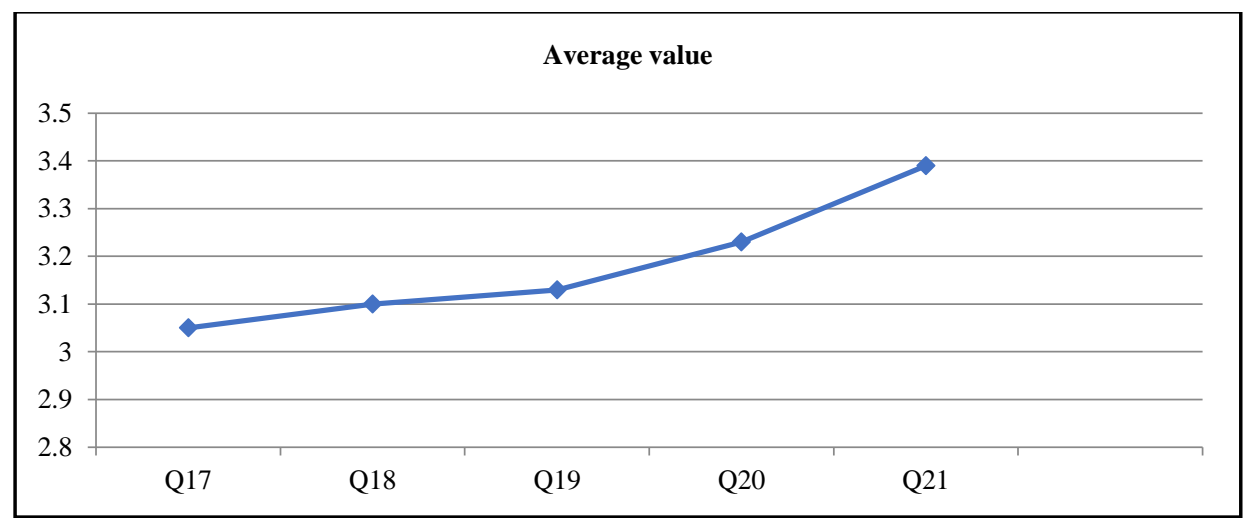

Figure 4. An Analysis of the Demands of College Students' Problem Solving.

From Figure 4, it can be seen that most of the students tend to complete the task in the form of group cooperation $(81.5 \%, \mathrm{Q} 17)$, and they tend to communicate with others to discuss solutions to the problem $(85.1 \%$, Q18). they also Said that in the cooperation with others can actively fulfill the task, almost all students (95.0\%) hope that their professional learning can get a professional certification or evaluation.

\section{College English Teaching Resources Database System Construction}

As shown in Figure 5, this model is generally a time progress model, which is formed by a combination of three main lines. The first is the project management process, which starts from the start of the project and undergoes master planning, execution monitoring, and final project evaluation. It is the specific construction activities and tasks of the college teaching resource bank at each stage. The third is the content of different project management at each stage. These three main lines clearly demonstrate the entire construction process and content management of the university teaching resource bank. 


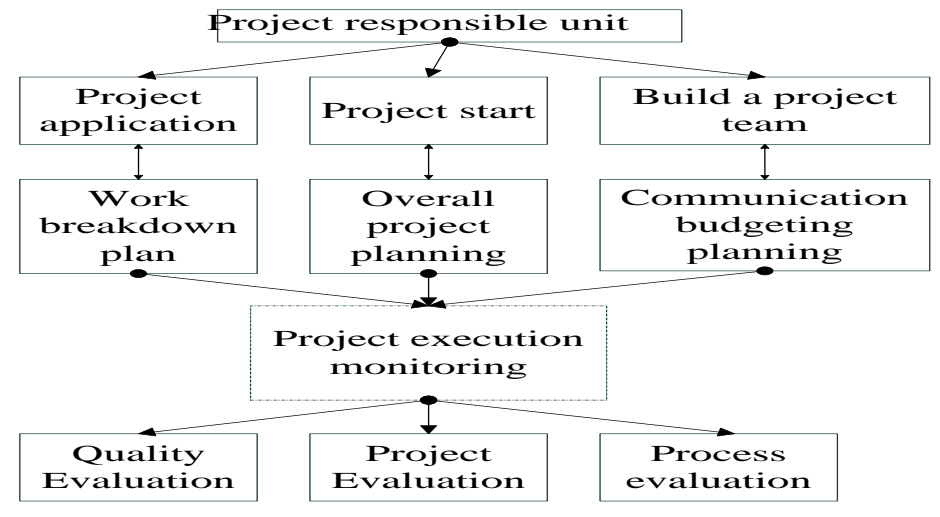

Figure 5. University Teaching Resources Database Construction Model Based on Project Management Theory.

1. Startup of college teaching resource bank construction project. The sign of project launch is that the project is approved for establishment. Any project must go through serious, scientific, and credible thinking and analysis. It is necessary to start the project as perfectly as possible and without defects. Ding Ronggui, at this stage, full investigation is very necessary. Feasibility analysis of the project is carried out on the basis of full investigation. The project with poor feasibility means failure from the beginning of the project. After the project is approved, the person in charge of the project needs to accurately locate the goal and scope of the construction of the teaching resource database, initially complete the project profile, and form a project team.

2. The overall plan for the construction of college teaching resources database. The tasks in the planning stage are based on the objective reality and aim at achieving the objectives of the project. The project plan for the start-up phase is further improved. The result of this phase is the formation of a schedule through a work breakdown plan. The main content includes further clarification of the key issues of the project. Create a work breakdown structure.

3. Construction and monitoring of university teaching resources database. During the construction and monitoring phase, the project team needs to take various actions to implement the project management plan and complete the tasks specified in the project. The project leader allocates manpower resources and corresponding resources to execute the construction of a single task package. A single task package is available through the work breakdown structure. After the completion of the construction, it is reviewed by the expert group to evaluate the cost, progress, and construction quality of the task package.

4. Evaluation of the construction of university teaching resources database. The evaluation of the project can be considered from the aspects of project management and project products. The project management association of the American Project Management Association and the evaluation of university teaching resources database construction project mainly reflect the self-assessment of team members and the evaluation project management of the project management process and the users' satisfaction with the teaching resources database. 


\section{Conclusion}

Into the Internet era, the content and functions of the teaching resource database have been continuously enriched and expanded. Teaching and learning based on the teaching resource database have caused the traditional teaching and learning activities to undergo tremendous changes. With the development of the informatization of vocational education in our country, the professional education resources library for professional education, which has invested huge human and financial resources, has received attention. The professional education resource library for professional education such as not only provides users with convenient and accessible teaching resources, but also provides users with a platform and environment for learning based on the Internet. We have been accustomed to evaluating resource pools from the perspective of "supply". We believe that the more resources in the resource bank the better, and the richer the better, but it ignores the user's "demand." Therefore, this study aims to focus on the issues that arise in the construction and use of the teaching resource pool from the perspective of the needs of higher vocational students, so as to reflect the real reasons why the teaching resource pool is not received. At the same time, cloud computing is a new kind of information technology. It applies cloud computing technology to the construction of digital teaching resources in universities, helps to integrate teaching resources, increases the sharing rate of teaching resources, solves the problem of uneven distribution of teaching resources, and reduces teaching. Cost, promote the improvement of teaching quality. With the rapid development and maturity of cloud computing technology, it will play an increasingly important role in teaching, research, and management services in universities.

\section{References}

Acharya, B. S., Actis, M., Aghajani, T., Agnetta, G., Aguilar, J., \& Aharonian, F., et al. (2013). Introducing the cta concept. Astroparticle Physics, 43(4), 3-18. http://dx.doi.org/10.1016/j.astropartphys.2013.01.007

Cook, S. G. (2014). Decision-making: when flipping a coin isn't good enough, Women in Higher Education, 21(2), 21-22. http://dx.doi.org/10.1002/whe.10294

Freire, C. E. D. A., \& Painho, M. (2014). Development of a Mobile Mapping Solution for Spatial Data Collection Using Open-source Technologies. Procedia Technology, 16, 481-490. http://dx.doi.org/10.1016/j.protcy.2014.10.115

Gupta, S., \& Gupta, B. B. (2018). XSS-secure as a service for the platforms of online social network-based multimedia web applications in cloud. Multimedia Tools and Applications, 77(4), 4829-4861. https://doi.org/10.1007/s11042-016-3735-1

Gaudencio, M., Dantas, A., \&Guerrero, D. S. (2014). Can computers compare student code solutions as well as teachers?. ACM Technical Symposium on Computer Science Education, 17(2), 418-423. http://dx.doi.org/10.1145/2538862.2538973 
James, P. S., Matthew, S., \& Samrachana, A. (2018). Constructing "experts" among peers: Educational infrastructure, test data, and teachers. Interactions About Teaching. Educational Evaluation and Policy Analysis, 40(4), 586-612. http://dx.doi.org/10.3102/0162373718785764

Lee, C. Y. (2012). Learning-by-doing in R\&D, knowledge threshold, and technological divide. Journal of Evolutionary Economics, 22(1), 109-132. http://dx.doi.org/10.1007/s00191-010-0202-4

Ma, S., Steger, D. G., Doolittle, P. E., \& Stewart, A. C. (2018). Improved Academic performance and student perceptions of learning through use of a cell phone-based personal response system. Journal of Food Science Education, 17(1), 27-32. https://doi.org/10.1111/1541-4329.12131

Sinnema, C. E. L., \& Fevre, D. L. (2013). When others' performance just isn't good enough: Educational leaders' framing of concerns in private and public. Leadership \& Policy in Schools, 12(4), 301-336. http://dx.doi.org/10.1080/15700763.2013.857419

Tan, P. J. B., \& Hsu, M. H. (2018). Designing a System for English Evaluation and Teaching Devices: A PZB and TAM Model Analysis. EURASIA Journal of Mathematics, Science and Technology Education, 14(6), 2107-2119. https://dx.doi.org/10.29333/ejmste/86467

Terhart, E. (2013). Teacher resistance against school reform: reflecting an inconvenient truth. School Leadership \& Management, 33(5), 486-500. http://dx.doi.org/10.1080/13632434.2013.793494

Tang, L. (2016). Exploration on cultivation of critical thinking in college intensive reading course. English Language Teaching, 9(3), 18. http://dx.doi.org/10.5539/elt.v9n3p18

Zhang, X. (2017). Field composition and development trend of research hotspots of translation technology in China-based on co-word visualization analysis of relevant academic journals from CNKI published from 1999 to 2017. Theory and Practice in Language Studies, 7(12), 1210-1221. http://dx.doi.org/10.17507/tpls.0712.07 